Supporting Information

\title{
Low Alkali Bottom-Up Synthesis of Titanate Nanotubes Using a Peroxo Titanium Complex Ion Precursor for Photocatalysis
}

Hyunsu Park, Tomoyo Goto, Do Hyung Han, Sunghun Cho, Hisataka Nishida, Tohru Sekino*

The Institute of Scientific and Industrial Research (ISIR), Osaka University, 8-1 Mihogaoka,

Ibaraki, Osaka, 567-0047, Japan

*Corresponding Author:

Tohru Sekino, Prof. Dr.

Tel: +81-6-6879-8435

E-mail: sekino@sanken.osaka-u.ac.jp 


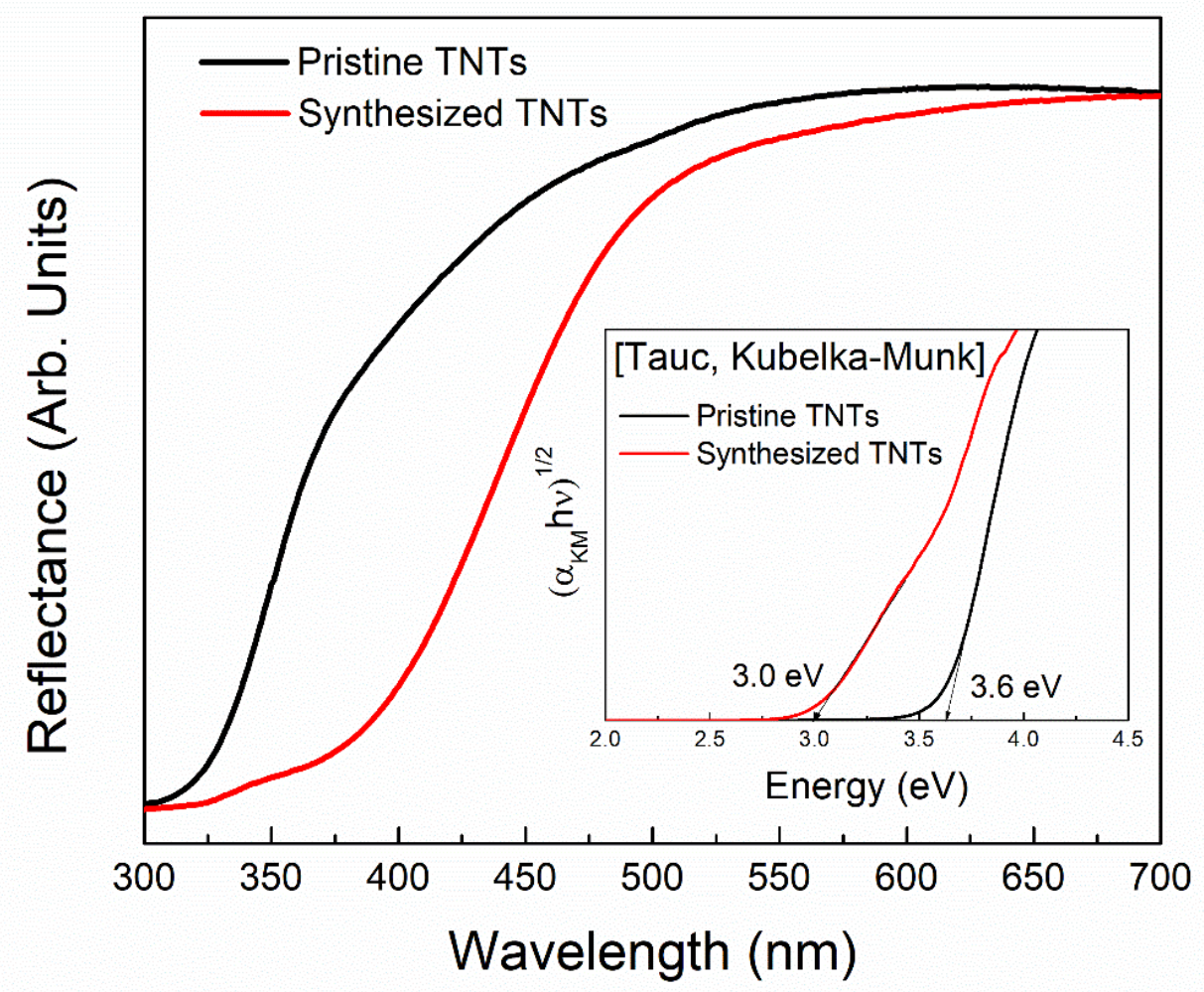

Figure S1. Ultraviolet-visible light (UV-vis) diffused reflectance spectra of pristine TNTs and synthesized TNTs. The insets show their Tauc plots using the Kubelka-Munk function by assuming indirect transition of semiconductor to observe the optical band gap energy.

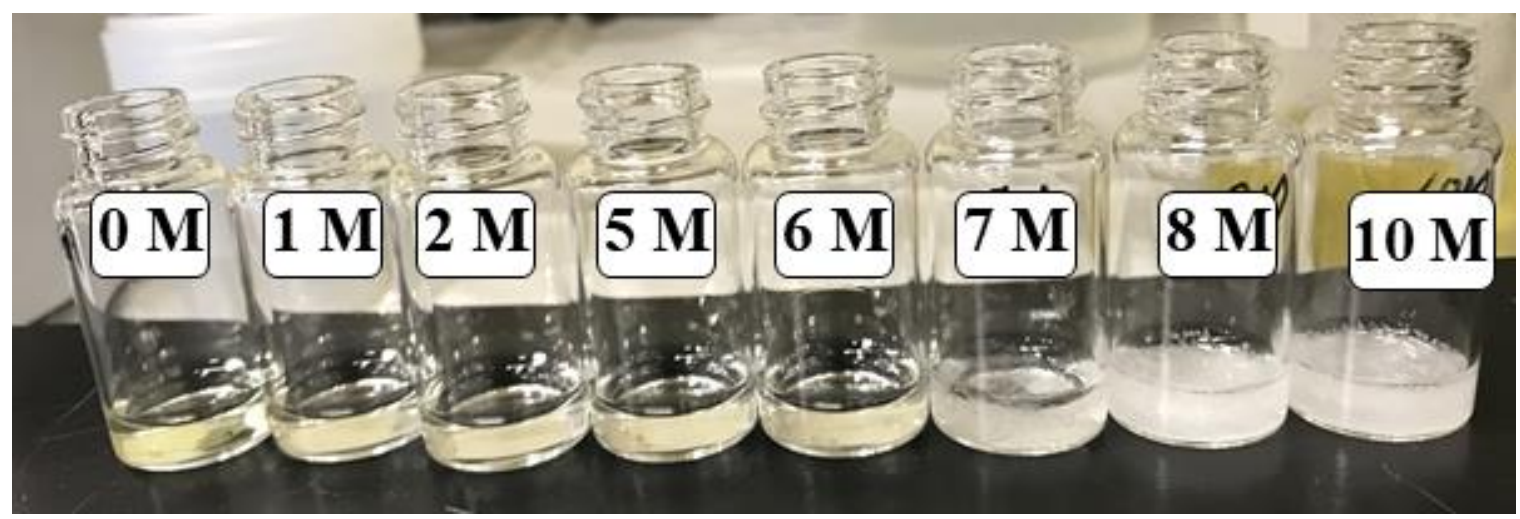

Figure S2. The appearance of the $\mathrm{NaOH}$ solution with concentrations range of $0-10 \mathrm{M}$ after the addition of prepared peroxo titanium complex ions solution. 


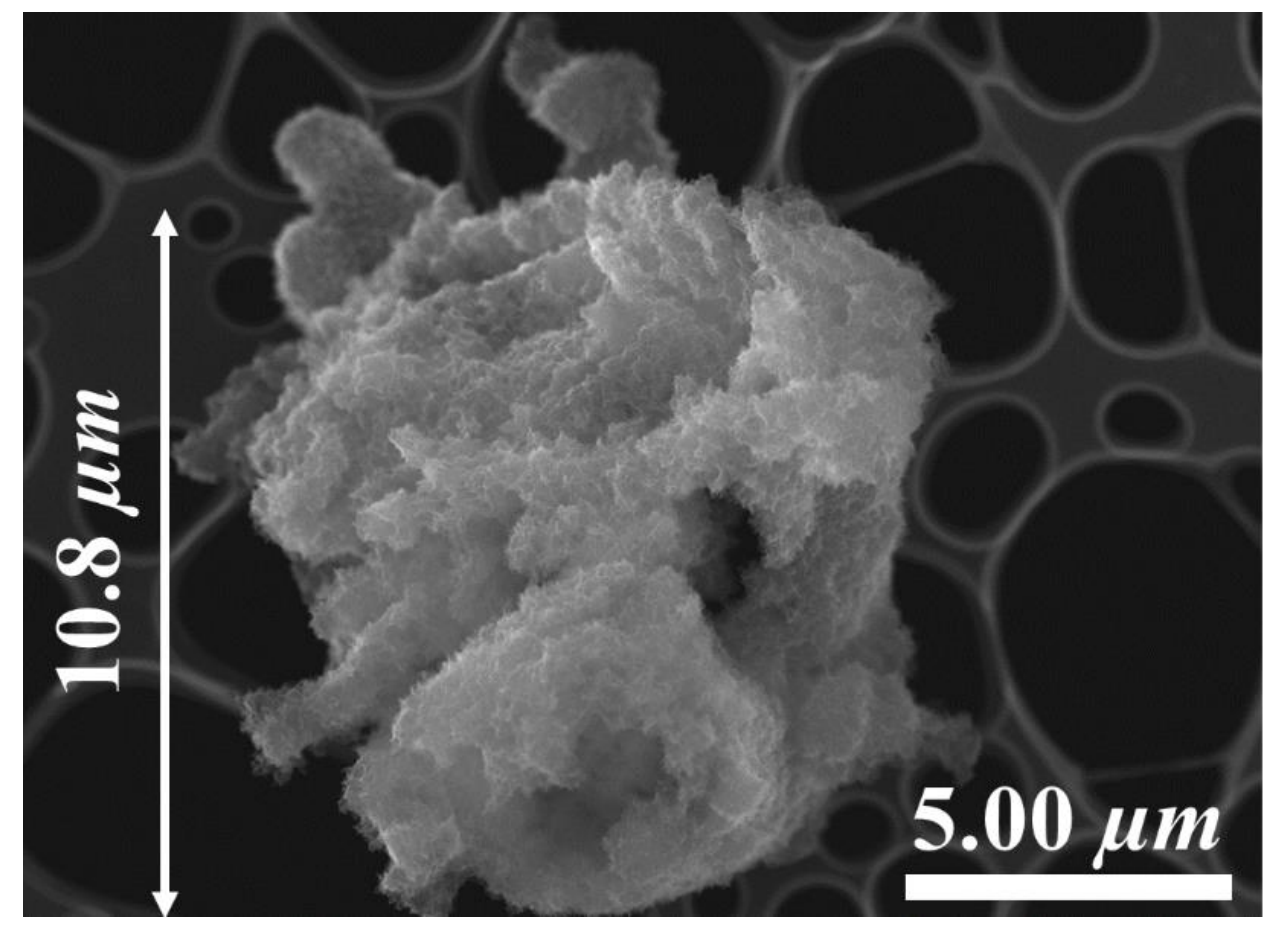

Figure S3. SEM image of precipitates obtained from $10 \mathrm{M} \mathrm{NaOH}$ solution adding peroxo titanium complex ions.
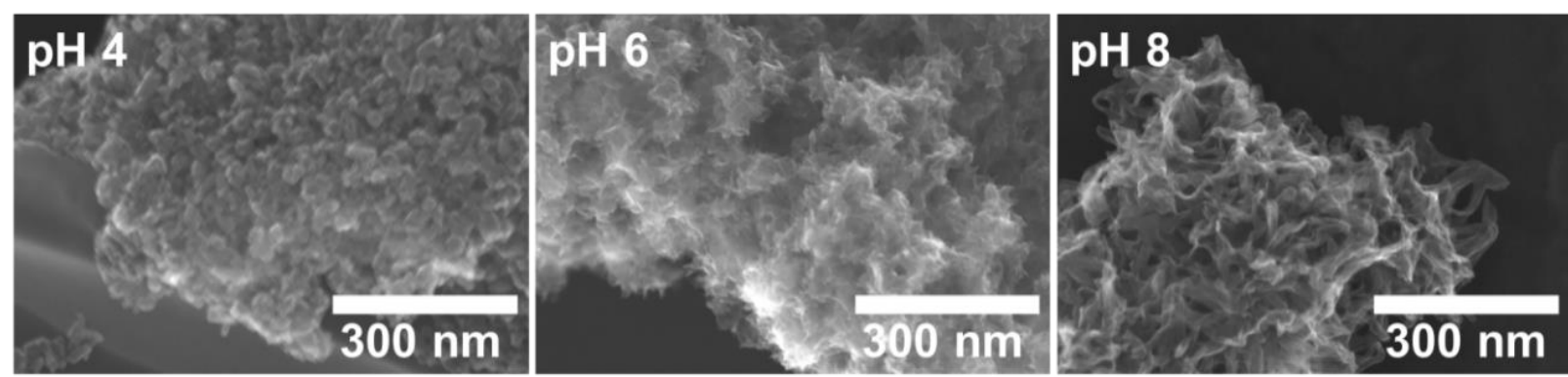

Figure S4. SEM images of titanate samples synthesized from the peroxo titanium complex ion precursor solutions having the different $\mathrm{pH}$ values of 4,6 , and 8 , respectively. The $\mathrm{pH}$ value was adjusted by gradually adding different amount of $\mathrm{NaOH}$ solution $(10 \mathrm{M})$ to the prepared peroxo titanium complex solution of which initial $\mathrm{pH}$ value was 4 . The sample of $\mathrm{pH} 4$ thus contained no sodium ion $\left(\mathrm{Na}^{+}\right)$. 